\title{
Comparison of 1-D seismic site response analysis tools for layered liquefiable deposits at an offshore windfarm site
}

\author{
Hao $\mathrm{Yu}^{1,{ }^{*}, \text { Eric Ntambakwa }}{ }^{2}$ and Bruno Mendes $^{3}$, \\ ${ }^{1}$ DNV GL, Renewables Advisory, 1601 Rio Grande St, Suite 400, Austin, TX, USA \\ ${ }^{2}$ DNV GL, Renewables Advisory, 9665 Chesapeake Drive, Suite 435, San Diego, CA, USA \\ ${ }^{3}$ DNV GL, Renewables Advisory, 4100 Rue Molson, \#100, Montreal, Canada
}

\begin{abstract}
Various offshore wind farms have been proposed in the Taiwan strait with a long-term target of installing 4.2 gigawatts by 2030 . The proposed projects will be in areas with various known faults and areal seismic sources which should be accounted for in design. A reliable prediction of site response for soil deposits is crucial for seismic loading evaluation of existing energy structures and for design of new structures including offshore wind farms in seismically active regions. This paper presents generic results of 1-D site response analyses based on work performed for an offshore wind power plant development site in the Taiwan strait. The deposits in the project area generally consist of layered deposits with liquefiable layers. The site response analyses were initially performed using two different open-source tools, DEEPSOIL and Cyclic 1D. Both equivalent linear and non-linear approaches were adopted for the analyses and additional evaluations were subsequently performed using PLAXIS 2D for comparison with the results from the open source tools. The results from the different tools were systematically compared and provided useful insight on peak ground (seabed) acceleration, acceleration time histories and shear strains at specific depths and design response spectra. The paper includes a discussion of the sensitivity of the outputs to various input parameters for each of the tools utilized in the analyses and the suitability and limitations of each approach for assessing liquefaction potential are also discussed.
\end{abstract}

\section{Introduction}

Long-term renewable energy targets have been set by Taiwanese Government with a particular focus on the development of offshore wind power capacity. However, the designated offshore wind power plant zones are within an area of high seismicity where comprehensive seismic risk assessments should be performed during design. A reliable prediction of site response, as part of a seismic risk assessment, is crucial for evaluating effects of subsurface conditions on ground motions for energy structures including offshore wind farms in seismically active regions.

The authors previously performed equivalent linear and non-linear site response analyses both for a generic offshore wind farm site in the Taiwan strait using DEEPSOIL and Cyclic 1D as presented in $\mathrm{Yu}$ et al. (2020). This paper presents results of additional 1-D site response analyses for the same site using PLAXIS 2D for comparison with the results from the prior assessment. A comparison of the results from the three tools has been performed to provide insight on peak ground (seabed) accelerations, cyclic stress ratios, acceleration time histories, shear strains and design response spectra at specific depths. Sensitivity of the results to various input parameters for each of the tools utilized in the analyses and the suitability and limitations for performing site response with each of the tools are also discussed. The comparisons discussed in this paper are limited to the models without consideration of pore pressure generation as assessment of the response considering pore pressure generation/liquefaction are ongoing.

\subsection{Seismic Setting and Source Characterization}

The time histories used in the site response analyses were selected from the PEER strong motion database by matching a target response spectrum for a representative coastal site near Miaoli City. The 475-year return period uniform hazard response spectrum for Miaoli City developed following the procedure in the Taiwan Building code (CPA, 2011) was utilized as the target spectrum. The approaches for seismic source characterization and event search parameters are presented in the reference paper by Yu et al. (2020).

Based on the characteristics of the major sources contributing to the hazard (faulting mechanism, Moment Magnitude, hypocenter distance), a total of 7 ground motions with the geometric mean response spectrum compatible with the target spectrum were selected and the events are shown in Table 1.

\footnotetext{
* Corresponding author: chris.yu@dnvgl.com
} 
Table 1. Selected Events for Spectrum-Compatible Time Histories

\begin{tabular}{|c|c|c|c|c|c|}
\hline Event & $\begin{array}{c}\text { Station } \\
\text { Name }\end{array}$ & $\mathbf{M}_{\mathbf{w}}$ & $\begin{array}{c}\mathbf{R}_{\mathbf{j b}} \\
(\mathbf{k m})\end{array}$ & $\begin{array}{c}\mathbf{R}_{\mathbf{r u p}} \\
(\mathbf{k m})\end{array}$ & $\begin{array}{c}\mathbf{V}_{\mathbf{s 3 0}} \\
(\mathbf{m} / \mathbf{s})\end{array}$ \\
\hline $\begin{array}{c}\text { Loma Prieta } \\
(89)\end{array}$ & $\begin{array}{c}\text { Palo Alto- } \\
\text { SLAC Lab }\end{array}$ & 6.9 & 30.6 & 30.9 & 425 \\
\hline Chi-Chi (99) & CHY029 & 7.6 & 11 & 11 & 545 \\
\hline Chi-Chi (99) & TCU042 & 7.6 & 26.3 & 26.3 & 579 \\
\hline $\begin{array}{c}\text { Hector Mine } \\
\text { (99) }\end{array}$ & Amboy & 7.1 & 41.8 & 43.1 & 383 \\
\hline $\begin{array}{c}\text { Cape } \\
\text { Mendocino } \\
\text { (92) }\end{array}$ & $\begin{array}{c}\text { Loleta Fire } \\
\text { Station }\end{array}$ & 7.0 & 23.5 & 25.9 & 516 \\
\hline $\begin{array}{c}\text { Chuetsu-0ki } \\
\text { Japan (07) }\end{array}$ & $\begin{array}{c}\text { Joetsu } \\
\text { Ogataku }\end{array}$ & 6.8 & 16.8 & 17.9 & 414 \\
\hline $\begin{array}{c}\text { Iwate Japan } \\
\text { (08) }\end{array}$ & $\begin{array}{c}\text { Matsuyama } \\
\text { City }\end{array}$ & 6.9 & 41 & 41 & 436 \\
\hline
\end{tabular}

*Mw: moment magnitude; Rjb: source-to-site distance; Rrup: rupture length

The number of selected events is consistent with typical requirements for site specific response analyses and the event characteristics are consistent with those reported by Cheng et al. (2007) for official seismic sources in Taiwan. A summary of the response spectra compared to the target spectrum is presented in Fig. 1.

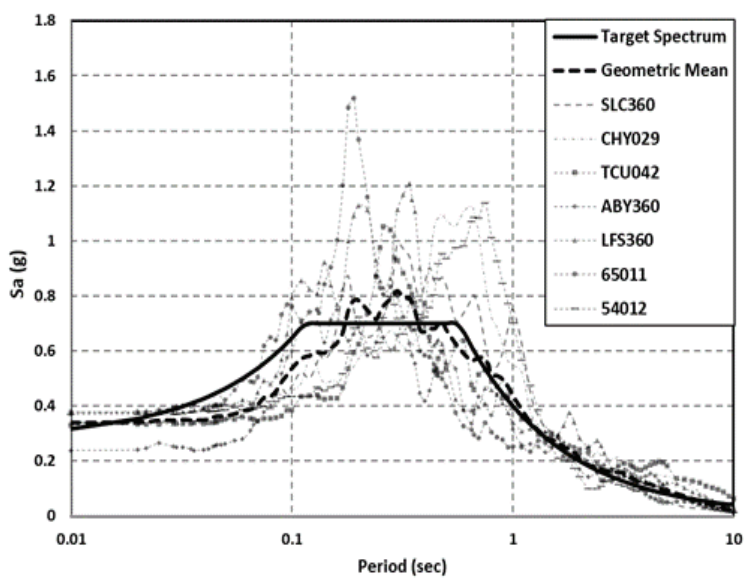

Fig. 1. Target and Selected Response Spectra Summary

\subsection{Geotechnical conditions}

Based on work performed by the authors for one of the wind farm areas in Taiwan strait, the generalized soil stratigraphy considered in this paper comprises a mixture of sand, silt and clay in the top 10 to 20 meters underlain by gravel and followed by bedrock. The soils at shallow depths are generally in a loose state and highly susceptible to liquefaction.

The representative soil profile and corresponding soil parameters were developed based on typical conditions from geotechnical investigations in the area as presented in Table 2. A series of field and laboratory tests, including Cone Penetration tests (CPT), P-S suspension logging, triaxial and cyclic triaxial tests and resonant column tests, were performed to determine general and advanced soil parameters. Other soil parameters used as input parameters for DEEPSOIL and CYCLIC 1D models and presented in $\mathrm{Yu}$ et al. (2020).

Table 2. Generalized soil stratigraphy and parameters

\begin{tabular}{|c|c|c|c|c|c|c|}
\hline Layer & $\begin{array}{c}\text { Top } \\
\text { of } \\
\text { unit } \\
\text { (m) }\end{array}$ & $\begin{array}{c}\text { Base } \\
\text { of } \\
\text { unit } \\
\text { (m) }\end{array}$ & $\begin{array}{l}\text { Soil } \\
\text { Type }\end{array}$ & $\begin{array}{c}\gamma \\
\left(k N / m^{3}\right)\end{array}$ & $\begin{array}{c}\boldsymbol{\sigma} \\
(\mathbf{d e g})\end{array}$ & $\begin{array}{c}\begin{array}{l}\text { Vs } \\
(\mathbf{m} / \mathbf{s})\end{array}\end{array}$ \\
\hline 1 & 0 & 2 & Sand & 18 & 28 & 67 \\
\hline 2 & 2 & 3 & Sand & 18 & 28 & 75 \\
\hline 3 & 3 & 4.5 & Sand & 19 & 28 & 57 \\
\hline 4 & 4.5 & 6 & Sand & 19 & 28 & 57 \\
\hline 5 & 6 & 7 & Silt & 18 & 24 & 57 \\
\hline 6 & 7 & 9.5 & Gravel & 22 & 58 & 241 \\
\hline 7 & 9.5 & 17.5 & Gravel & 22 & 59 & 343 \\
\hline 8 & 17.5 & - & Bedrock & 22 & - & 600 \\
\hline
\end{tabular}

$\left(\gamma\right.$ : unit weight; ø: Friction angle; $\mathrm{V}_{\mathrm{s}}$ : shear wave velocity)

\subsection{PLAXIS 2D Model}

The 1-D site response analysis was performed for free field conditions using PLAXIS 2D. The soil deposits are modelled as a soil column with the Hardening soil with small strain stiffness constitutive model (HS small model) to account for the non-linear behavior of soil under dynamic loading. Compared to the Hardening soil model that has been widely used for conventional geotechnical engineering numerical models, the HS small model is extended by introducing two additional parameters, the shear modulus at small strain level $\mathrm{G}_{0}$, and the shear strain at which shear modulus has reduced to $70 \%$ of the initial value $\left(\gamma_{0.7}\right)$, to simulate the changes of hysteretic damping and stiffness (Plaxis, 2018). Other stiffness parameters used as input are the tangent stiffness for primary oedometric loading $\left(E_{o e d}\right)$, and the unloading/reloading stiffness from drained triaxial tests $\left(E_{\mathrm{ur}}\right)$. The primary input parameters for the Plaxis model are summarized in Table 3 .

The lateral boundary conditions for 1-D wave propagation were modelled as tied degrees of freedom in which the nodes at the left and right boundaries, on the same elevation, are connected to each other and experience equal displacement during application of dynamic loading (Plaxis, 2015). The ground motion was assumed to be applied at the bedrock level (on the bottom of soil deposit) and was modelled by imposing a prescribed displacement at the bottom boundary.

Table 3. Summary of generalized soil stratigraphy/parameters

\begin{tabular}{|c|c|c|c|c|c|c|}
\hline Layer & $\begin{array}{c}\text { Unit } \\
\text { Top } \\
(\mathbf{m})\end{array}$ & $\begin{array}{c}\text { Unit } \\
\text { Base } \\
(\mathbf{m})\end{array}$ & $\begin{array}{c}\text { Soil } \\
\text { Type }\end{array}$ & $\begin{array}{c}\text { E50 } \\
\mathbf{( k P a )}\end{array}$ & $\begin{array}{c}\mathbf{G} \text { 0 } \\
\mathbf{( k P a )}\end{array}$ & $\boldsymbol{\gamma}_{\mathbf{0 . 7}}$ \\
\hline 1 & 0.0 & 2.0 & Sand & 941 & 8237 & $7 \mathrm{E}-5$ \\
\hline 2 & 2.0 & 3.0 & Sand & 1270 & 3811 & $8 \mathrm{E}-5$ \\
\hline 3 & 3.0 & 4.5 & Sand & 559 & 6293 & $9 \mathrm{E}-5$ \\
\hline 4 & 4.5 & 6.0 & Sand & 559 & 6293 & $1 \mathrm{E}-4$ \\
\hline 5 & 6.0 & 7.0 & Silt & 530 & 5961 & $1 \mathrm{E}-4$ \\
\hline 6 & 7.0 & 9.5 & Gravel & $2.6 \mathrm{E} 4$ & $1.3 \mathrm{E} 5$ & $2 \mathrm{E}-3$ \\
\hline 7 & 9.5 & 17.5 & Gravel & $8.4 \mathrm{E} 4$ & $2.6 \mathrm{E} 5$ & $2 \mathrm{E}-3$ \\
\hline
\end{tabular}

$* \mathrm{E}_{50}$ : secant stiffness; $\mathrm{E}_{\mathrm{oed}}=\mathrm{E}_{50} ; \mathrm{E}_{\mathrm{ur}}=3 . \mathrm{E}_{\mathrm{oed}}$ 


\section{Site Response Analyses}

\subsection{Dynamic Soil Model Parameters}

It is necessary to define appropriate modulus reduction and damping curves for all the soil layers in performing site response analysis. The analysis utilizes an iterative procedure to obtain strain compatible values of shear modulus and damping based on the modulus and damping relationships defined for each layer. Based on the parameter values for each layer listed in Table 3, the corresponding modulus reduction and damping curves in the HS Small model were compared to those obtained using relationships developed by Darendeli (2001) for validation. The comparison indicated good consistency between the two datasets.

It should be noted that the modulus reduction and damping curves in the HS Small model have a cut-off strain level beyond which the shear modulus remains constant. The cut-off corresponds to a strain level beyond which the tangent shear modulus cannot reduce below the secant shear modulus value (Plaxis, 2015). The implementation allows for appropriate estimation of material damping above the cut-off strain level.
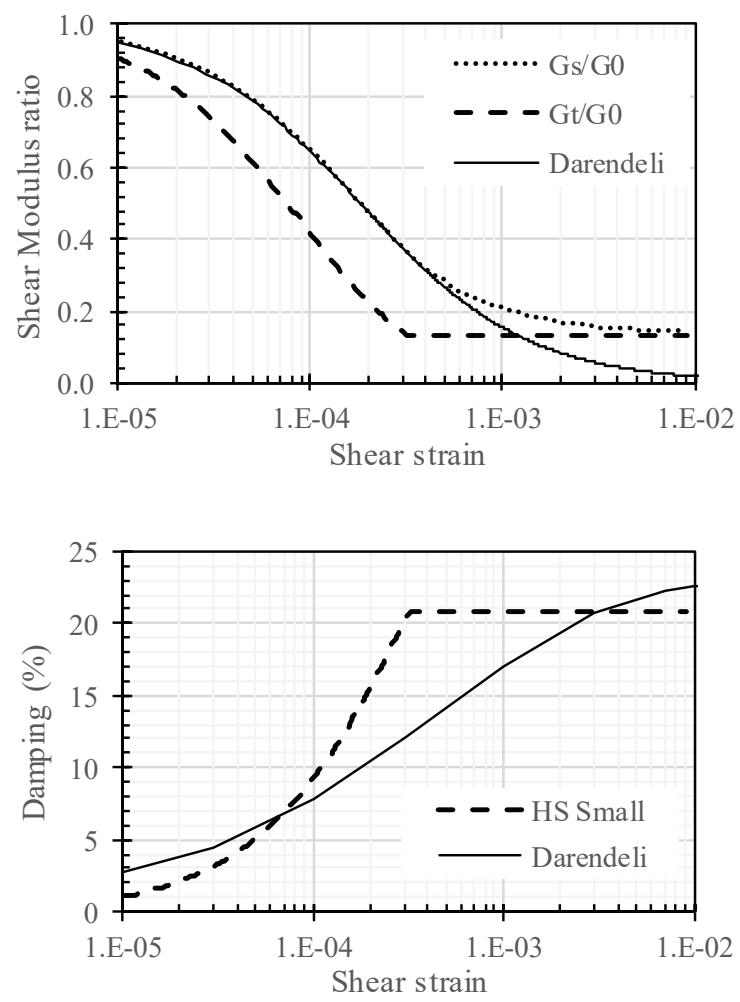

Fig. 2. Darendeli (2001) and HS Small modulus reduction and damping curve comparison for Layer $1\left(\mathrm{G}_{\mathrm{s}}\right.$ : secant shear modulus; $\mathrm{G}_{\mathrm{t}}$ : tangent shear modulus)

\subsection{Input Motion}

For dynamic analyses in Plaxis 2D, the acceleration time history can be specified in terms of a prescribed displacement at the base of the soil model. The boundary conditions at the base of the model were set to a compliant base and the motion was therefore scaled by $50 \%$ as specified in the user manual for the selected boundary condition (Plaxis, 2015). Due to the limitation of data point to 10,000 , the acceleration time histories of the original records were truncated by removing some of the zero acceleration data points to meet the limit in the program while preserving the content of the time history records.

\subsection{Analysis Results}

Results of the analyses are presented in Figures 3 through 7 below. The results include comparison of maximum horizontal acceleration, cyclic stress ratio, maximum shear strain and displacement, stress-strain response, acceleration time histories at a depth of $6.5 \mathrm{~m}$ below seabed and corresponding acceleration response spectra. Overall, the analyses indicate consistent results across the different tools. The summaries do however indicate scatter in some of the results although the overall range of values appears to be within reasonable bounds of uncertainty. The results from the Plaxis 2D analysis indicate nearly constant max stress ratios above a depth of about $6 \mathrm{~m}$ below seabed compared to increases in max stress ratios for the Cyclic 1D and DEEPSOIL results. The difference may be due to a larger reduction in stiffness for the Plaxis 2D model within that layer as is shown in the stress-strain response in Figure 6.

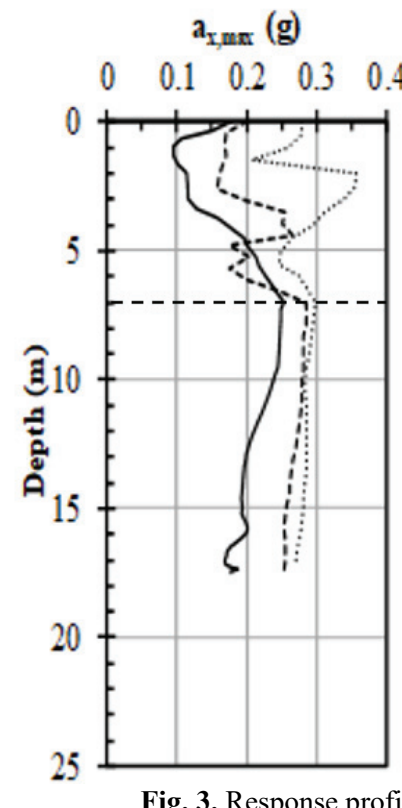

\section{Max stress ratio}

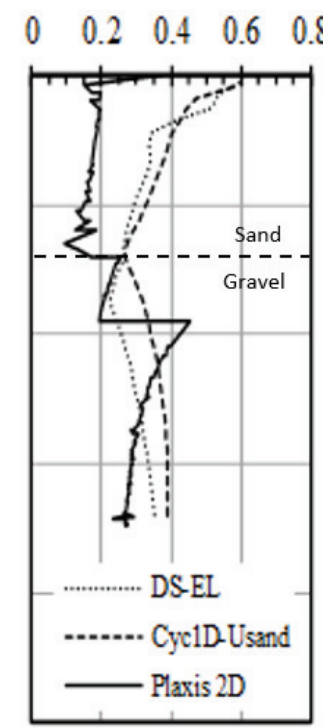

Fig. 3. Response profiles - CHY029EW 


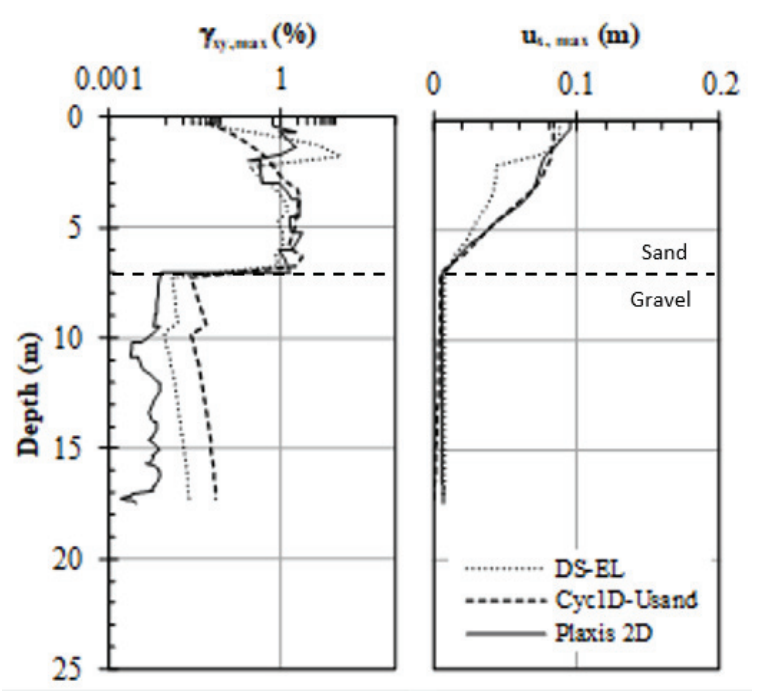

Fig. 4. Response profiles - CHY029EW
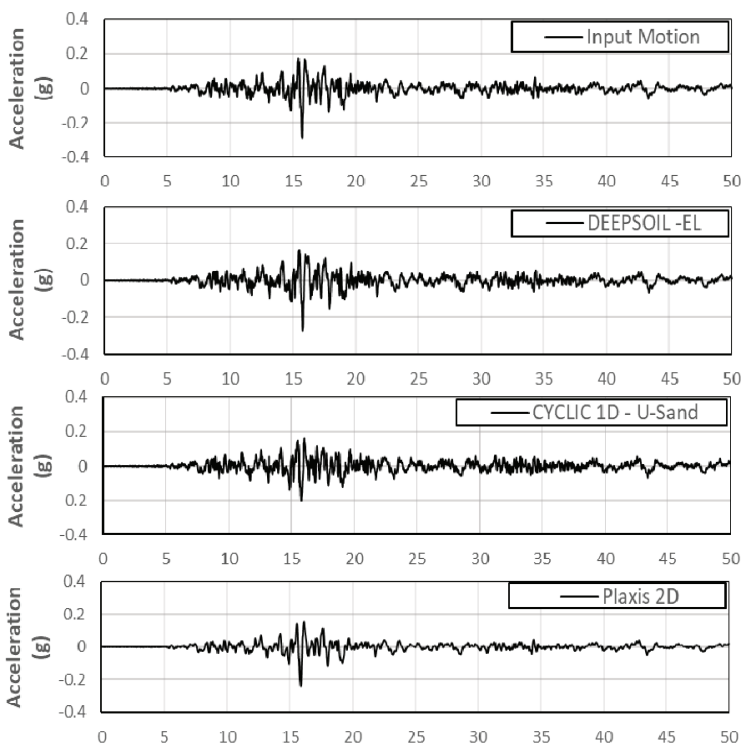

Fig. 5. Time history responses - CHY029EW, depth: $6.5 \mathrm{~m}$

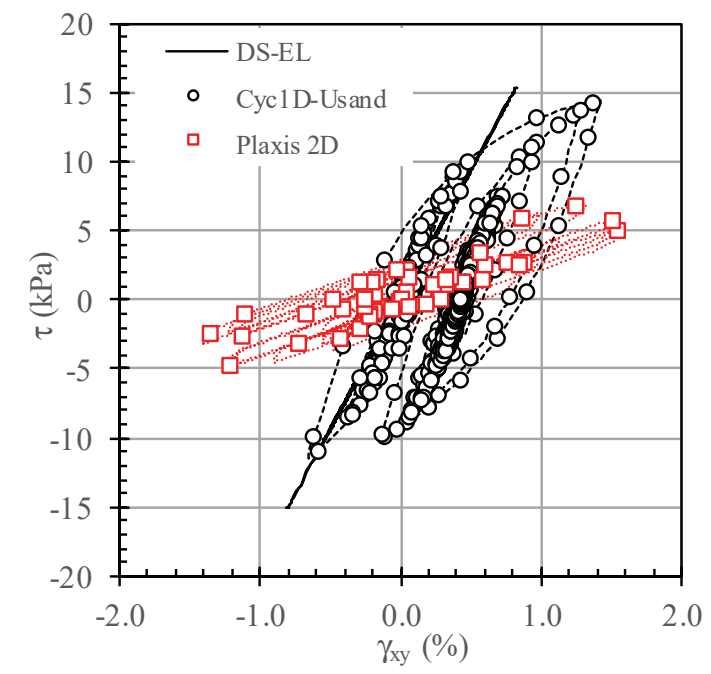

Fig. 6. Stress-strain curve - CHY029EW, depth: 6.5m

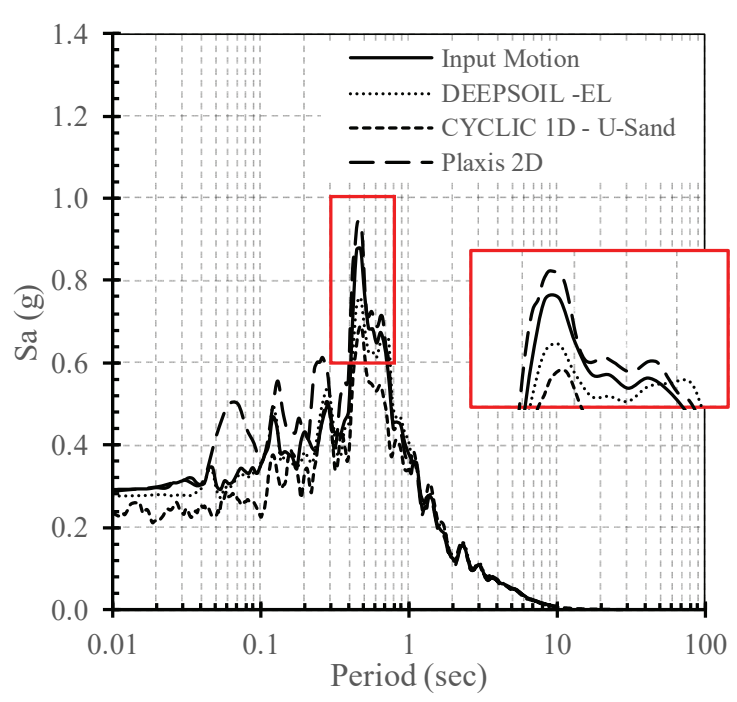

Fig. 7. Comparison of response spectrum of acceleration CHY029EW, depth: $6.5 \mathrm{~m}$

\section{DISCUSSION AND CONCLUSIONS}

Site response analysis is an important part of seismic risk assessment for offshore wind farm development and accounts for the propagation of the seismic waves through various soil and rock media that influence the energy, frequency content and other inherent characteristics of ground motions. Compared to prescriptive seismic design parameters in typical building codes or published literature, site response analysis facilitates more robust analyses of potential seismic effects including liquefaction assessment and advanced structural stability analysis for the wind turbines and associated infrastructure, and installation vessels.

Based on the evaluations performed, it is possible to obtain consistent site response results using different tools available in industry. Each of the tools has various merits and limitations and may be utilized for site response analysis depending on the desired application or user preference.

The tools compared in this assessment were based on consistent soil profiles and corresponding properties to facilitate a direct comparison of the results. The primary input parameter for each layer was the shear wave velocity which defines the initial stiffness of each of the layers and therefore the impedance contrast and transfer function at each layer boundary. There are differences in the methodology for calculating the evolution of shear strains, stiffness reduction and damping during wave propagation in each of tools evaluated. The tools are however able to provide consistent results for the same soil stratigraphy and input parameter values.

The analysis model in DEEPSOIL is relatively straight forward to set up and includes modules for curve fitting modulus reduction and damping curves and for visualizing the soil mode input as well as the ground motion metrics. The program is also able to quite efficiently run multiple ground motions at the same time during the analyses and has a graphical interface for 
reviewing the results. The ground surface is assumed to be flat in the DEEPSOIL analyses and the user is able to select soil layers or specific depths for generation of results.

In Cyclic-1D, the analysis model is essentially set up as a finite element mesh at a desired resolution. Unlike the DEEPSOIL and the HS Small model used in Plaxis 2D which use iterative procedures to obtain strain compatible values of shear modulus and damping based on modulus and damping relationships, Cyclic 1D employs an incremental plasticity model to allow for modelling permanent deformation and for generation of hysteretic damping (Elgamal, et al. 2015). The primary input parameters are however relatively straight forward for the model without pore pressure generation and soil properties can easily be assigned to each of the elements (soil layers). The program also allows for the model to be inclined up to 10 degrees from horizontal.

For Plaxis 2D, setting up the analysis model is relatively more involved including definition of the constitutive model parameters, setting up appropriate boundary conditions and defining the ground motion as a prescribed displacement. For the HS Small constitutive model utilized for this assessment, it is important to ensure that realistic values of the initial value $\gamma_{0.7}$ are selected to appropriately simulate the changes of hysteretic damping and stiffness during the analysis. Ideally, this should be based on dynamic soil testing or suitable empirical relationships if reliable soil testing data is unavailable. It is also important to ensure that the ground motion is scaled by $50 \%$ if the compliant boundary condition is being implemented. Although not directly assessed by the authors in this research, one of the strengths of using Plaxis 2D is that the structure being evaluated can be included in the model and the response evaluated in a coupled manner during application of the ground motion.

The reviewed tools can be utilized for site response analyses based on user preference or goals of the evaluations. For evaluations that require running a large number of motions, it appears that DEEPSOIL is a reasonable tool to utilize. Cyclic $1 \mathrm{D}$ offers the ability to run a finite element-based model using various predefined soil models or with user-defined models that are relatively straight forward to set up. In addition, it allows for performing site response analyses at sloping ground conditions. The model set-up for Plaxis 2D was relatively more involving but it offers the ability for direct analysis of seismic loading impact on structures which can be included in the model for assessment of response as the ground motion is being applied.

\section{References}

1. C. Cheng, S. Chiou, C. Lee, T. Tsai, Study on Probabilistic Seismic Hazard Maps of Taiwan After Chi-Chi Earthquake, J. GeoEng, Vol.2, No.1, 19-28, (2007)

2. A. Elgamal, Z. Yang, J. Lu "Cyclic 1D Seismic Ground Response Version 1.4 User's Manual." (2015)
3. M.B. Darendeli, "Development of a New Family of Normalized Modulus Reduction and Material Damping Curves", Ph.D. Thesis, Department of Civil, Architectural and Environmental Engineering, The University of Texas, Austin, Texas (2001)

4. CPA, Seismic Design Code and Commentary for Buildings, 2011 Edition, Construction and Planning Agency, Ministry of Interior Affairs, Taipei, Taiwan (2011)

5. D. Groholski, Y. Hashash, B. Kim, M., Musgrove, J. Harmon, J Stewart "Simplified Model for SmallStrain Nonlinearity and Strength in $1 D$ Seismic Site Response Analysis." J. Geotech. Geoenviron. Eng. Vol.142, No.9, (2016).

6. Y. Hashash, M. Musgrove, J. Harmon, O. Ilhan, D. Groholski, C. Phillips, DEEPSOIL 7.0, User Manual. (2017).

7. N. Matasovic, M. Vucetic, "Cyclic Characterization of Liquefiable Sands." ASCE J. Geotech. Geoenviron. Eng., 119 (11), pp 1805-1822.(1993)

8. C. Phillips, Y. Hashash. "Damping formulation for non-linear $1 D$ site response analyses." Soil Dynamics and Earthquake Engineering, 29, pp 1143-1158. (2009)

9. H. Yu., E. Ntambakwa, B. Mendes, M. Rogers, Comparison of 1-D Seismic Site Response Analysis Tools for Layered Liquefiable Deposits, Proc. ASCE Geo-Congress 2020 (In Publication).

10. PLAXIS, Site Response analysis and liquefaction evaluation (2015)

11. PLAXIS, Plaxis 2D reference manual (2018)

12. I. Alpan. The Geotechnical Properties of Soils, Elsevier, Earth-Science Reviews, Vol. 6, No. 1, pp. 5-49 (1970). 